\title{
The anti-erbB3 antibody MM-121/SAR256212 in combination with trastuzumab exerts potent antitumor activity against trastuzumab-resistant breast cancer cells
}

Jingcao Huang ${ }^{1,2+}$, Shuiliang Wang ${ }^{1,4+}$, Hui Lyu' ${ }^{1}$, Bo Cai ${ }^{1}$, XiaoHe Yang ${ }^{3}$, Jianxiang Wang ${ }^{2^{*}}$ and Bolin Liu ${ }^{1 *}$

\begin{abstract}
Background: Elevated expression of erbB3 receptor has been reported to induce resistance to therapeutic agents, including trastuzumab in erbB2-overexpressing breast cancer. Our recent studies indicate that erbB3 interacts with both erbB2 and IGF-1 receptor to form a heterotrimeric complex in trastuzumab-resistant breast cancer cells. Herein, we investigate the antitumor activity of MM-121/SAR256212, a fully human anti-erbB3 antibody (Ab), against two erbB2-overexpressing breast cancer cell lines resistant to trastuzumab.
\end{abstract}

Methods: MTS-based proliferation assays were used to determine cell viability upon treatment of trastuzumab and/or MM-121/SAR256212. Cell cycle progression was examined by flow cytometric analysis. Western blot analyses were performed to determine the expression and activation of proteins. Tumor xenografts were established by inoculation of the trastuzumab-resistant BT474-HR20 cells into nude mice. The tumor-bearing mice were treated with trastuzumab and/or MM-121/SAR256212 via i.p injection to determine the Abs' antitumor activity. Immunohistochemical analyses were carried out to study the Abs' inhibitory effects on tumor cell proliferation and induction of apoptosis in vivo.

Results: MM-121 significantly enhanced trastuzumab-induced growth inhibition in two sensitive and two resistant breast cancer cell lines. MM-121 in combination with trastuzumab resulted in a dramatic reduction of phosphorylated erbB3 (P-erbB3) and Akt (P-Akt) in the in vitro studies. MM-121 combined with trastuzumab did not induce apoptosis in the trastuzumab-resistant cell lines under our cell culture condition, rather induced cell cycle G1 arrest mainly associated with the upregulation of $p 27^{\mathrm{kip} 1}$. Interestingly, in the tumor xenograft model established from the trastuzumab-resistant cells, MM-121 in combination with trastuzumab as compared to either agent alone dramatically inhibited tumor growth correlated with a significant reduction of Ki67 staining and increase of cleaved caspase-3 in the tumor tissues.

Conclusions: The combination of MM-121 and trastuzumab not only inhibits erbB2-overexpressing breast cancer cell proliferation, but also promotes the otherwise trastuzumab-resistant cells undergoing apoptosis in an in vivo xenografts model. Thus, MM-121 exhibits potent antitumor activity when combined with trastuzumab under the studied conditions. Our data suggest that further studies regarding the suitability of MM-121 for treatment of breast cancer patients whose tumors overexpress erbB2 and become resistant to trastuzumab may be warranted.

Keywords: MM-121, SAR256212, erbB3, erbB2, Trastuzumab resistance, Breast cancer

\footnotetext{
*Correspondence: wangjx@ihcams.ac.cn; bolin.liu@ucdenver.edu

${ }^{\dagger}$ Equal contributors

${ }^{2}$ State Key Laboratory of Experimental Hematology, Institute of Hematology

and Blood Disease Hospital, 288 Nanjing Road, Tianjin 300020, China

'Department of Pathology, School of Medicine, University of Colorado

Anschutz Medical Campus, MS-8104, 12801 E. 17th Ave., Aurora, CO 80045,

USA

Full list of author information is available at the end of the article
} 


\section{Background}

Amplification and/or overexpression of erbB2 (or HER2/ $n e u$ ) occur in approximately $25 \%$ of invasive breast cancer and are significantly associated with a worse prognosis for breast cancer patients [1-3]. As an erbB2-targeted therapy, trastuzumab (also known as Herceptin, a humanized monoclonal antibody (Ab) against erbB2) has been approved by FDA and demonstrated significant activity in the treatment of breast cancer patients with erbB2-overexpressing (erbB2+) tumors [4-6]; however, both primary (de novo) and acquired resistances to trastuzumab are common and currently represent a significant clinical problem [7-9]. Thus, identification of novel therapeutic strategies/agents to overcome trastuzumab resistance is vital to improve the survival of breast cancer patients whose tumors overexpress erbB2.

Studies on the underlying mechanisms suggest that increased resistance to therapeutic agents is one of the major mechanisms by which erbB2 contributes to breast tumorigenesis [10]. Nonetheless, erbB2 does not act in isolation. It often interacts with other receptor tyrosine kinases (RTKs), such as erbB3, to activate the oncogenic signaling, like PI-3K/Akt pathway, in breast cancers [11]. Co-expression of erbB3 and erbB2 is frequently observed in breast cancers [12] and breast cancer cell lines [13], and erbB3 plays an important role in breast cancer development driven by erbB2 amplification/overexpression [14]. It has been shown that erbB3 serves as a critical co-receptor of erbB2, and its expression is a rate-limiting factor for erbB2-induced breast cancer cell survival and proliferation $[14,15]$. Unlike the widely studied erbB2 and EGFR in human cancers, there has been relatively less emphasis on erbB3 as a molecular target for cancer treatment. Currently used erbB2-targeted therapies in clinic can be divided into two strategies: blocking $\mathrm{Ab}$, such as trastuzumab targeting erbB2; and tyrosine kinase inhibitor, such as lapatinib against both EGFR and erbB2. For the erbB3 receptor, because of its lack of or low kinase activity $[16,17]$, targeting of erbB3 with a monoclonal Ab is the only strategy currently under preclinical investigation $[18,19]$ and clinical studies in patients with advanced solid tumors (http://www.clinicaltrials.gov). Recent studies have also identified bispecific Abs dual-targeting of EGFR/erbB3 [20] or erbB2/erbB3 [21], that exhibit potent antitumor activities in laboratory studies. In addition, the erbB3 inhibitors based on a novel biologic scaffold termed a surrobody have been developed and show inhibitory effects on tumor cell proliferation in vitro and in vivo [22]. MM$121 /$ SAR256212 is a fully human anti-erbB3 monoclonal IgG2 Ab being co-developed by Merrimack Pharmaceuticals and Sanofi. It inhibits ligand-induced dimerization of erbB3 and erbB2 and subsequently inactivates the downstream signaling. MM-121 has been demonstrated to exert antitumor activity in preclinical models of human cancers, including erbB2+ breast cancer $[18,19]$. However, whether MM-121 holds potential to overcome trastuzumab resistance and enhance trastuzumab-mediated growth inhibition in erbB2+ breast cancer cells remains unclear.

Mechanistic studies implicate the function of erbB3 as a major cause of treatment failure in human cancers [23]. In the last several years, our laboratory has focused on studying the biologic features of erbB3 receptor in erbB2+ breast cancer, and published a serious of articles indicating that activation of erbB3 signaling, mainly through PI-3K/ Akt pathway, is essential for erbB2-induced therapeutic resistance to tamoxifen [24], paclitaxel [25], and trastuzumab [26]. Interestingly, activation of the PI-3K/Akt signaling has been identified as the major determinant of trastuzumab resistance [27]. Indeed, our recent studies with the unique trastuzumab-resistant breast cancer model demonstrate that the erbB3 receptor interacts with both erbB2 and the insulin-like growth factor-1 receptor (IGF-1R) to form a heterotrimeric complex, which mainly activates the PI-3K/Akt signaling and Src kinase and subsequently leads to trastuzumab resistance [26]. We hypothesized that the anti-erbB3 Ab MM-121 can overcome trastuzumab resistance and enhance the efficacy of trastuzumab against erbB2+ breast cancer. In the current study, we investigated the potential of MM-121 in combination with trastuzumab on inducing growth inhibition and/or apoptosis in two trastuzumab-sensitive and two trastuzumab-resistant breast cancer cell lines in vitro, and explored their inhibitory effects on the growth of tumor xenografts-derived from a trastuzumab-resistant breast cancer cell line in vivo.

\section{Results}

MM-121 significantly enhances the inhibitory effects of trastuzumab on erbB2+ breast cancer cell lines associated with the inactivation of erbB3/PI-3K/Akt signaling

To explore whether the anti-erbB3 Ab MM-121 may enhance the activity of trastuzumab against erbB2+ breast cancers, we investigated the combinatorial effects of MM121 and trastuzumab on erbB3 signaling and cell proliferation in two erbB2+ breast cancer cell lines (SKBR3 and BT474). The cells were treated with either MM-121 or trastuzumab alone, or their combinations for $24 \mathrm{hrs}$, and then subjected to western blot analysis. We found that treatment with trastuzumab mainly reduced the levels of phosphorylated erbB3 (P-erbB3) and phosphorylated Akt (P-Akt) in both SKBR3 and BT474 cell lines, whereas MM-121 had no obvious effects on P-erbB3 and P-Akt. However, the combinations of MM-121 and trastuzumab more potently decreased P-erbB3 and P-Akt as compared to trastuzumab alone in SKBR3 cells and to a less extend in BT474 cells (Figure 1A). Neither MM-121 or trastuzumab alone, nor their combinations had significant effects on erbB2 kinase activity, MAPK signaling, and the expression 


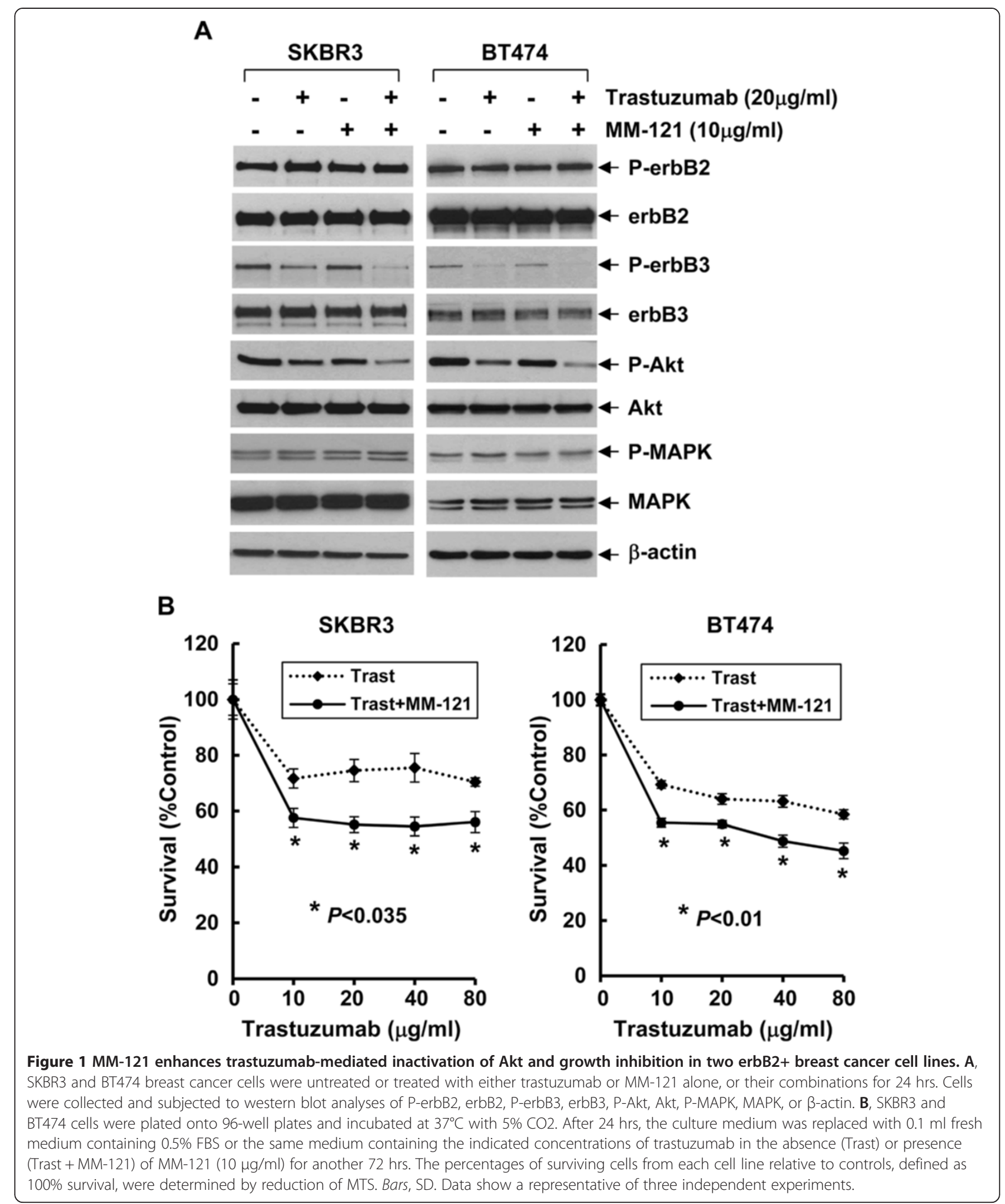

of erbB2/erbB3 receptors (Figure 1A). Cell growth assays revealed that trastuzumab inhibited proliferation of SKBR3 and BT474 cell lines in a dose-dependent manner, consistent with our previous findings [26]. The addition of
MM-121 significantly enhanced trastuzumab-mediated growth inhibition in both SKBR3 and BT474 cell lines (Figure 1B). Since activation of the erbB3 signaling plays an important role in the development of trastuzumab 
resistance [26], we next studied whether MM-121 might overcome the resistance and enhance trastuzumabmediated growth inhibition in two otherwise resistant breast cancer cell lines. SKBR3-pool2 and BT474-HR20 are trastuzumab-resistant sublines-derived from SKBR3 and BT474 cell lines, respectively $[26,28]$. While SKBR3-pool2 cells were kindly provided by Dr. Francisco Esteva at MD Anderson Cancer Center [28,29], the BT474-HR20 subline was developed by our laboratory through continuously exposing BT474 cells to trastuzumab in culture for 4 months [26,30]. Indeed, both SKBR3-pool2 and BT474-HR20 cells maintained their resistant phenotype to trastuzumab treatment as compared to their sensitive counterparts (Figure 2A vs Figure 1B). However, the presence of MM-121 significantly enhanced trastuzumabmediated growth inhibition in both SKBR3-pool2 and BT474-HR20 cell lines (Figure 2A). Further studies on erbB3 activation and the downstream signaling showed that while either MM-121 or trastuzumab alone induced a clear reduction of P-erbB3 and P-Akt and had no significant effects on P-erbB2 and P-MAPK, the combinations of MM-121 and trastuzumab dramatically reduced P-erbB3 and P-Akt in both SKBR3-pool2 and BT474-HR20 cell lines (Figure $2 \mathrm{~B}$ ). Taken together, our data indicate that the erbB3 blocking Ab MM-121 significantly enhances trastuzumab-induced growth inhibition in two erbB2+ breast cancer cell lines and exhibits potential to overcome trastuzumab resistance mainly through inactivation of the erbB3/PI-3K/Akt signaling.

\section{MM-121 in combination with trastuzumab induces cell cycle $\mathrm{G} 1$ arrest in both trastuzumab-sensitive and -resistant breast cancer cell lines}

To study the molecular mechanism by which MM-121 overcomes trastuzumab resistance and enhances trastuzumab's efficacy on inhibition of cell proliferation and/or survival in the studied cell lines, we considered the mechanism of action of trastuzumab inducing cell cycle G1 arrest $[4,31,32]$ and thus investigated the combinatorial effects of MM-121 and trastuzumab on the expression levels of several critical molecules participating in G1-S transition and cell cycle progression in erbB2+ breast cancer cell lines. In the trastuzumab-sensitive cells, trastuzumab alone induced a minor reduction of E2F-1 and a slight increase of p2 $7^{\text {kip1 }}$ in SKBR3 cells, and it only upregulated p2 $7^{\text {kip1 }}$ in BT474 cells (Figure 3A). MM-121 alone did not alter the expression levels of E2F-1 and p27 ${ }^{\text {kip } 1}$ in either cell lines. However, the combinations of trastuzumab and MM-121 clearly increased the levels of $\mathrm{p} 27^{\mathrm{kip} 1}$ in both cell lines and led to a minor reduction of E2F-1 in SKBR3 cells (Figure 3A). The expression levels of cyclin D1 were not significantly changed upon treatment with trastuzumab and/or MM-121. Flow cytometry analysis of cell cycle distribution showed that trastuzumab alone increased the cells at G1 phase in both cell lines, whereas MM-121 enhanced G1 population only in SKBR3 cells. Importantly, MM-121 in combination with trastuzumab more dramatically increased the percentage cells at G1 phase and decreased the cells at $\mathrm{S}$ phase in both cell lines (Figure 3B), suggesting a further induction of G1 arrest. In the trastuzumab-resistant cells, the expression levels of p $27^{\text {kip1 }}$ were slightly increased upon treatment with either trastuzumab or MM-121 alone, whereas the combinations of MM-121 and trastuzumab not only upregulated p2 $7^{\text {kip1 }}$ in both SKBR3-pool2 and BT474-HR20 cell lines, but also decreased E2F-1 in SKBR3-pool2 cells (Figure 4A). Furthermore, cell cycle analysis confirmed that the combinations of MM-121 and trastuzumab exhibited more potent activity than either agent alone to increase the G1 population and decrease the cells at $S$ phase (Figure 4B). MM-121 and/or trastuzumab had no significant effect on G2-M transition in both trastuzumab-sensitive and -resistant cells (Figures 3B \& 4B). While Figures 3B and 4B show the representative data, statistical analyses of G1 population from multiple cell cycle assays were also performed, and we found that the combinations of MM-121 and trastuzumab as compared to trastuzumab alone significantly increased G1 population in SKBR3, SKBR3-pool2, and BT474-HR20 cells (Additional file 1: Figure S1). Additional studies on induction of apoptosis showed that MM-121 and/or trastuzumab did not induce apoptosis in our cell culture condition (data not shown). Collectively, our studies suggest that the combinations of MM-121 and trastuzumab inhibited proliferation of both trastuzumab-sensitive and trastuzumab-resistant breast cancer cells mainly through cell cycle G1 arrest, which was correlated with the upregulation of $\mathrm{p} 27^{\mathrm{kip} 1}$ and sometimes a concomitant downregulation of E2F-1.

The combinations of MM-121 and trastuzumab significantly inhibit growth of tumor xenografts-established from a trastuzumab-resistant breast cancer cell line in nude mice

To further explore whether MM-121 holds potential to overcome trastuzumab resistance in an in vivo model for breast cancer treatment, we took advantage of the tumor xenografts model established from the trastuzumabresistant breast cancer cell line BT474-HR20. There is a general concern that erbB2+ breast cancer cell lines are difficult to form spontaneous xenografts in athymic nu/ nu mice [33], and it is not known whether the BT474HR20 cells would maintain their trastuzumab-resistant phenotype in vivo. We first compared the ability of trastuzumab-sensitive and -resistant cells to form tumors in nude mice. We found that the BT474-HR20 cells formed tumors with a shorter latency than BT474 cells, and the tumors established from the resistant cells grew significantly faster than those from the parental cells (Additional file 2: Figure S2A), suggesting the 


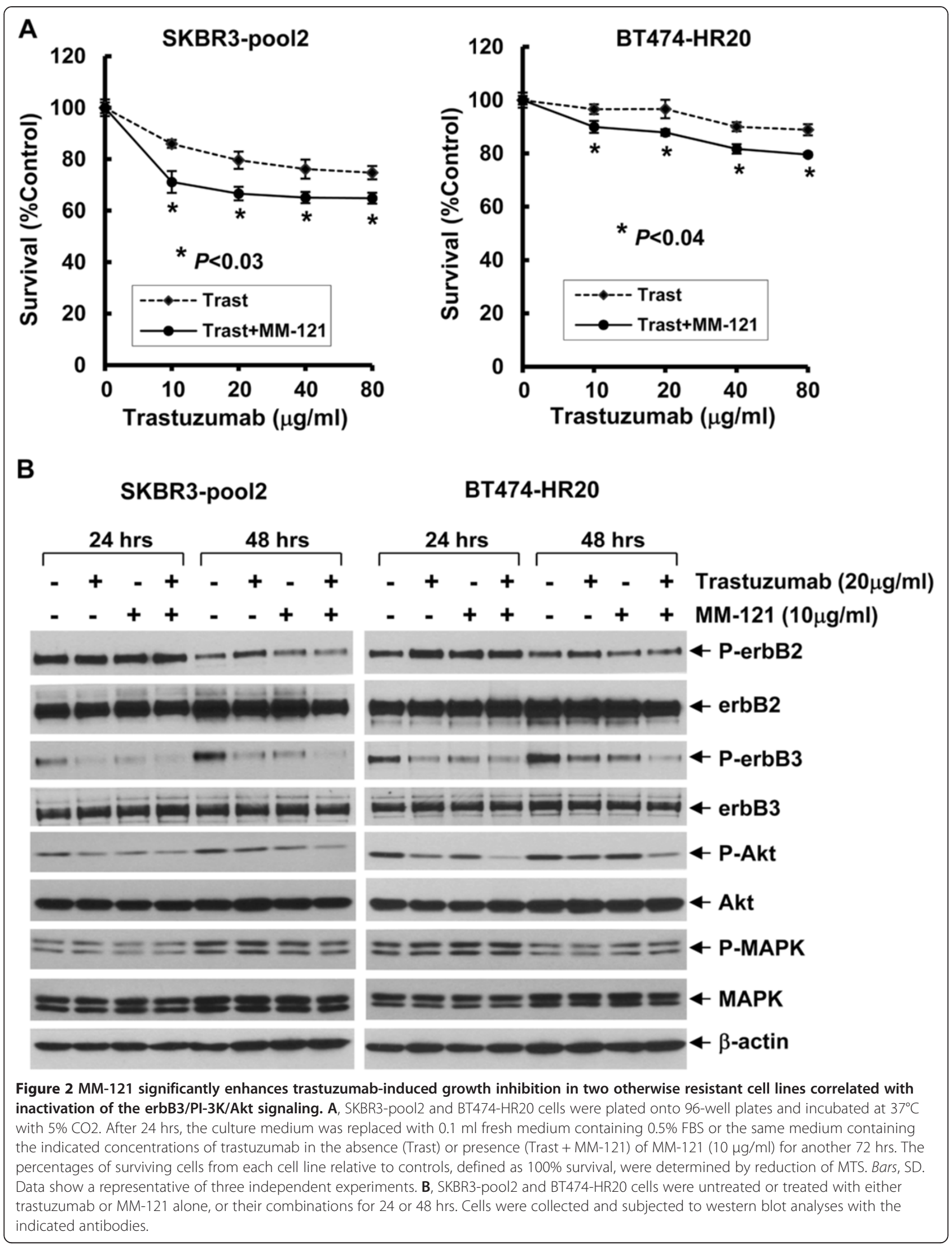




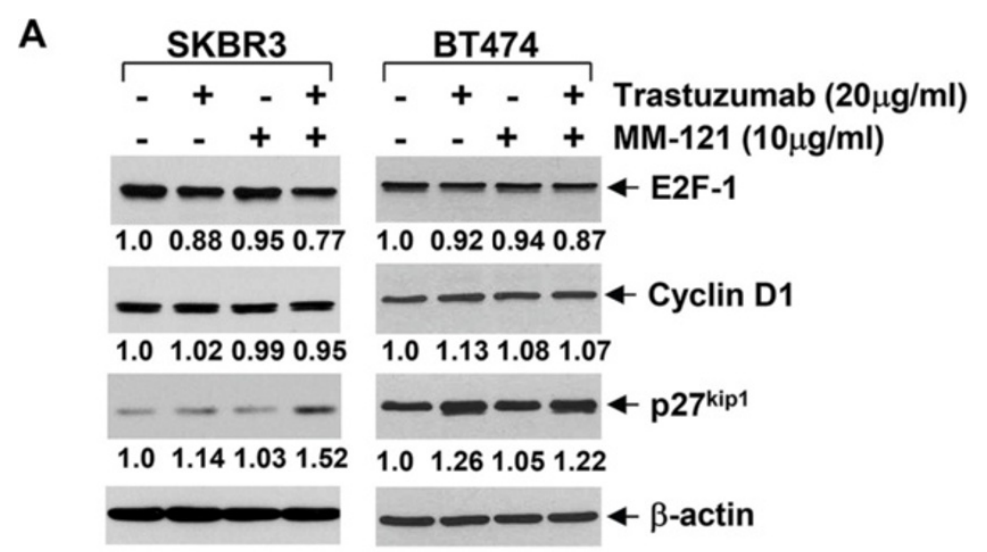

B

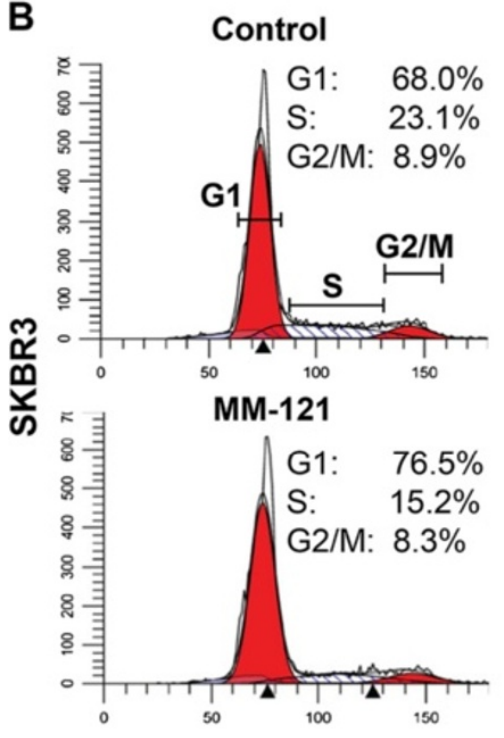

C
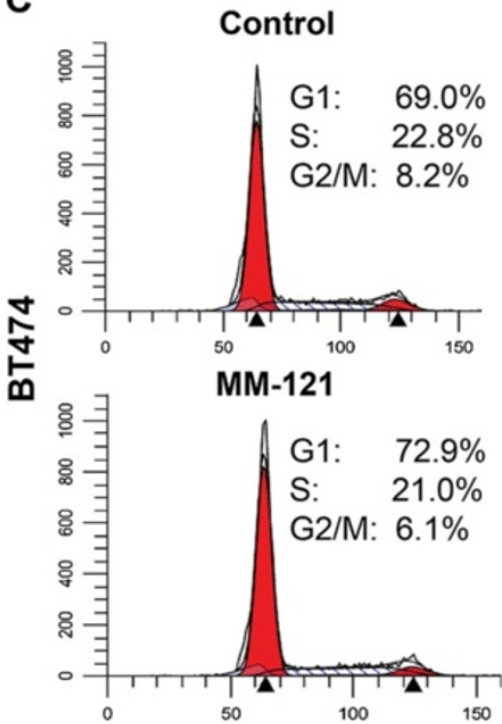

Trastuzumab

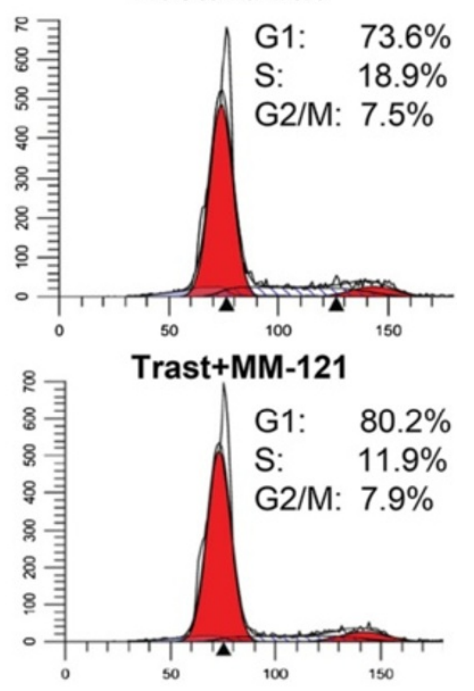

Trastuzumab

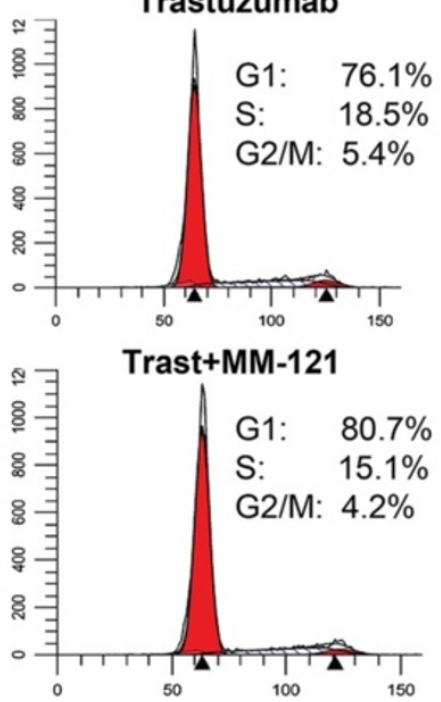

Figure 3 (See legend on next page.) 
(See figure on previous page.)

Figure 3 The addition of MM-121 enhances trastuzumab-induced cell cycle G1 arrest in erbB2+ breast cancer cell lines. SKBR3 and BT474 cells were untreated or treated with either trastuzumab or MM-121 alone, or their combinations for 24 hrs. A, Half of the cells were

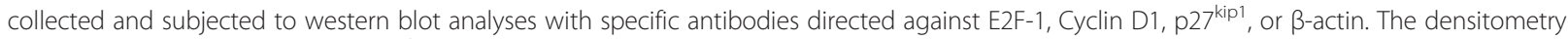
analyses of E2F-1, Cyclin D1, and p2 $7^{\text {kip } 1}$ signals were shown underneath, and the arbitrary numbers indicate the intensities of each sample relative to controls, defined as 1.0. B \& C, The other half of the cells were collected for analysis of cell cycle distributions by flow cytometry as described in the Materials and Methods. Data show a representative of three independent experiments.

aggressive phenotypes of BT474-HR20 cells. Importantly, the tumors-derived from BT474-HR20 cells were still growing under the treatment of trastuzumab (Additional file 2: Figure S2B), whereas the tumorsderived from BT474 cells were eliminated after three doses of trastuzumab (Additional file 2: Figure S2C). These data suggest that although BT474-HR20 cells were obtained in in vitro cell culture condition, they still maintained the trastuzumab-resistant phenotype in vivo. We next performed the following in vivo experiments with Ab treatment. When BT474-HR20 tumor volumes reached $\sim 65 \mathrm{~mm}^{3}$, the nude mice were treated with either PBS (control), or MM-121 or trastuzumab alone, or the combinations of MM-121 and trastuzumab. Treatment with trastuzumab alone resulted in a minor and statistically insignificant inhibition (Figure 5A). It appeared that MM-121 alone had a stimulatory effect on the growth of BT474-HR20 tumor xenograft, although the differences were statistically insignificant. However, this phenomenon was not observed consistently. In our recent publication, MM-121 alone had neither positive nor negative effect on in vivo tumor growth of BT474HR20 cells . More importantly, the combinations of MM121 and trastuzumab significantly inhibited tumor growth of BT474-HR20 cells (Figure 5A). After 6-time treatments, the remaining tumors from the combinatorial treatment were very small. We did observe tumor regression in the time frame of our experiments. Histology and immunohistochemistry (IHC) assays revealed that treatment with MM-121 or trastuzumab alone did not alter tumor cell morphology and the expression of erbB2/erbB3 receptors (Figure 5B). In contrast, the combinatorial treatment resulted in much less tumor cells remaining, lost tumor architecture, and increased fibroblast cells in the tissues. Nonetheless, the remaining tumor cells maintained a similar expression levels of both erbB2 and erbB3 receptors (Figure 5B), which was consistent with the results of our cell culture studies (Figure 2B).

MM-121 enhances trastuzumab's antitumor activity against the otherwise resistant breast cancer cells via induction of both cell growth inhibition and apoptosis in vivo

While our cell culture studies discovered that MM-121 in combination with trastuzumab inhibited proliferation of SKBR3-pool2 and BT474-HR20 cell lines (Figure 2A) without induction of apoptosis (data not shown), we wondered whether the combinations of MM-121 and trastuzumab would have similar effects on the trastuzumabresistant cells in vivo. By utilizing the tumor tissues obtained from the BT474-HR20 xenograft animal studies described above, we then performed IHC studies on the classic cell proliferative marker Ki67 and cleaved caspase-3, an indicative of cells undergoing apoptosis. The mice treated with MM-121 or trastuzumab exhibited a minor reduction in the number of tumor cells with positive staining of Ki67 as compared to the control mice (Figure 6A). Neither MM-121 nor trastuzumab induced caspase-3 cleavage in the tumor tissues. However, the mice treated with both MM-121 and trastuzumab showed a dramatic reduction in the number of tumor cells with positive staining of Ki67 and a significant increase of the tumor cells with cleaved caspase-3 (Figure 6 and Additional file 3: Figure S3). These data indicate that MM-121 enhances trastuzumab's antitumor activity against the otherwise resistant breast cancer cells via induction of both cell growth inhibition and apoptosis in this in vivo model.

\section{Discussion}

As a unique member of the erbB receptor family, erbB3 has long been considered an inactive "pseudokinase" $[16,34]$. A recent study suggests that erbB3 has weak kinase activity that can trans-autophosphorylate its intracellular region [17]. In order to fully transduce cell signaling, however, erbB3 has to be phosphorylated by its interactive partners, of these, erbB2 is the most important one [35]. It has been well-documented that activation of the erbB3 signaling plays a pivotal role in the development of erbB2+ breast cancer [14,15], castration-resistant prostate cancer [36], platinum resistant/refractory ovarian cancer $[37,38]$, and etc. Nonetheless, no erbB3-targeted therapy has been approved for cancer treatment. MM-121 is an erbB3 blocking Ab that is being actively investigated, mainly in combination with chemotherapy, in clinical trials of cancer patients with solid tumors, such as advanced non-small cell lung cancer, colorectal cancer, squamous cell head \& neck cancer, platinum resistant/ refractory ovarian cancer (http://www.clinicaltrials.gov/ ct $2 /$ results?term $=\mathrm{mm}-121$ ). In breast cancer, MM-121's therapeutic potential is being tested in patients with ER and/or PR positive and erbB2 negative breast cancers in combination with the aromatase inhibitor exemestane, 
A
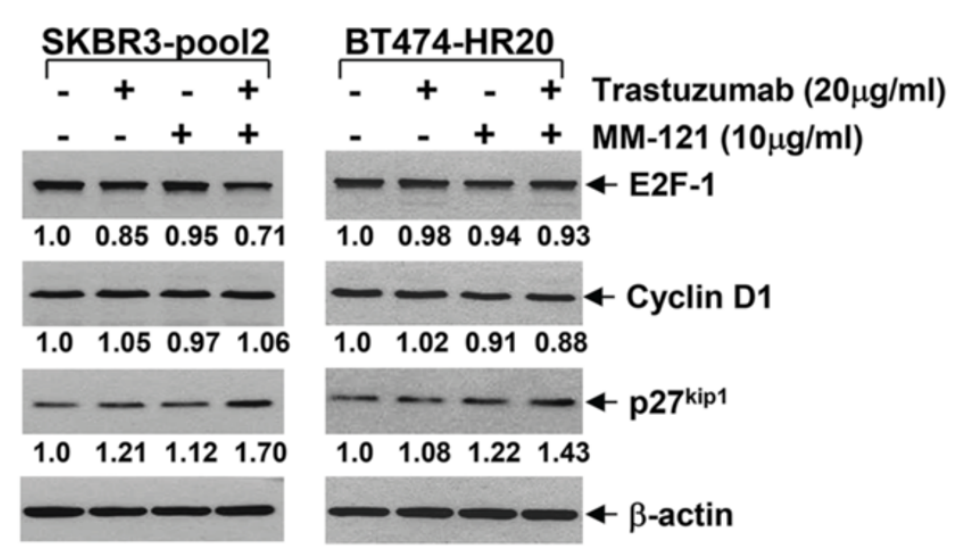

B

Control

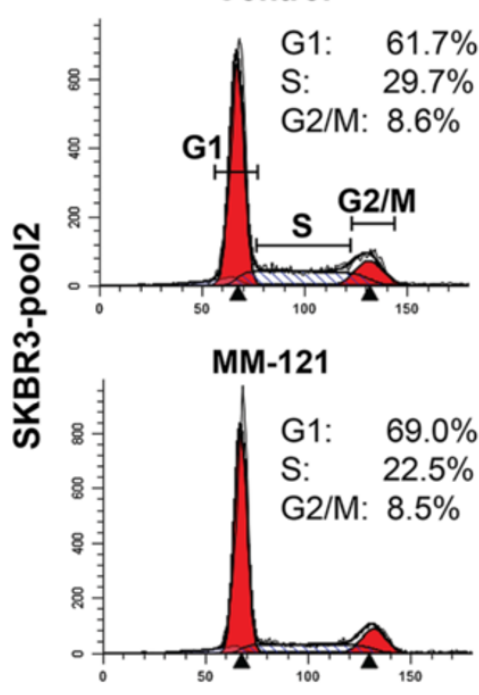

Trastuzumab

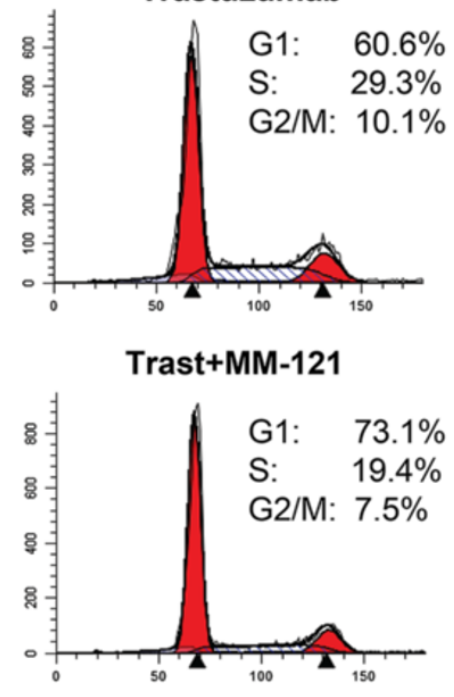

C

Trastuzumab
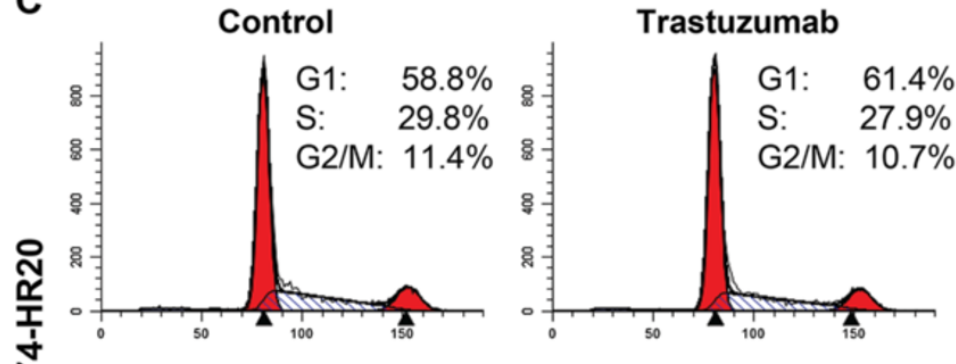

守

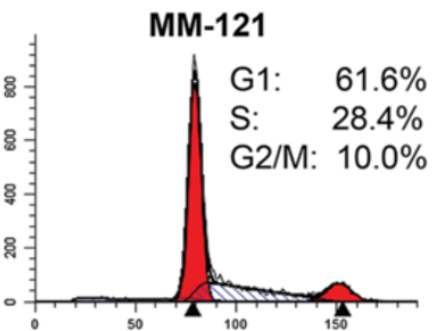

Trast+MM-121

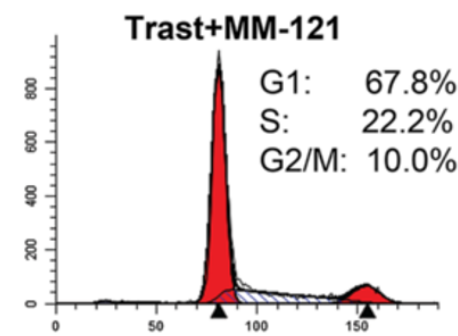

Figure 4 (See legend on next page.) 
(See figure on previous page.)

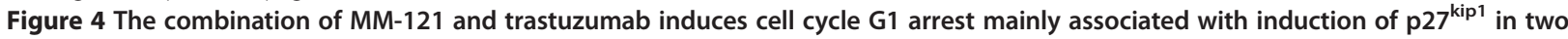
trastuzumab-resistant cell lines. SKBR3-pool2 and BT474-HR20 cells were untreated or treated with either trastuzumab or MM-121 alone, or their combinations for 24 hrs. A, Half of the cells were collected and subjected to western blot analyses with specific antibodies directed against E2F-1, Cyclin D1, p27 kip1, or $\beta$-actin. The densitometry analyses of E2F-1, Cyclin D1, and p27 kip1 signals were shown underneath, and the arbitrary numbers indicate the intensities of each sample relative to controls, defined as 1.0. B \& $\mathbf{C}$, The other half of the cells were collected for cell cycle analysis. Data show a representative of three independent experiments.

and in patients with triple negative or erbB2 negative breast cancers in combination with paclitaxel. To date, no clinical study has been initiated to test MM-121's activity in breast cancer patients with erbB2+ tumors, particularly those become resistant to trastuzumab. Here, we demonstrated that MM-121 significantly enhanced trastuzumabmediated growth inhibition in two sensitive and two resistant breast cancer cell lines. More importantly, the studies using a specific tumor xenograft model further proved that MM-121 exerted potent activity to overcome trastuzumab resistance in that in vivo model. Thus, our data provide a strong basis to explore the therapeutic potential of MM-121 in combination with trastuzumab in erbB2+ breast cancer patients resistant to trastuzumab.

Our previous studies showed that the mechanism of trastuzumab resistance in SKBR3-pool2 and BT474-HR20 cells was due to the formation of a heterotrimeric complex consisting of erbB2, erbB3, and IGF-1R [26]. We discovered that the expression of both erbB3 and IGF-1R was critical for maintaining trastuzumab-resistant phenotype, since specific knockdown of either erbB3 or IGF-1R significantly abrogated the resistance in SKBR3-pool2 and BT474-HR20 cells [26]. The data presented here indicated that inhibiting erbB3, but retaining its expression, also resensitized the resistant cells to the treatment of trastuzumab in our in vitro (Figure 2) and in vivo (Figure 5) models. It is not clear, however, whether inactivation of erbB3 by MM-121 overcomes trastuzumab resistance via disrupting the heterotrimerization of erbB2/erbB3/ IGF-1R. At this moment, the molecular basis of this heterotrimerization remains unknown. We speculate that long-term exposure of SKBR3 or BT474 cells to trastuzumab may induce expression of the ligands for erbB3 (heregulin, HRG) and IGF-1R (IGF-I and/or IGF-II), which could subsequently recruit all three RTKs together to form the unique heterotrimeric complex. Since MM121 inhibits ligand-induced dimerization between erbB3 and erbB2 [18,19], it may also interfere with the heterotrimeric complex consisting of erbB2, erbB3, and IGF-1R in SKBR3-pool2 and BT474-HR20 cells and thus overcome the resistance. However, detailed studies are warranted to test this hypothesis.

The combinations of MM-121 and trastuzumab inhibited proliferation of two sensitive and two resistant breast cancer cell lines in vitro; however, they induced both growth inhibition and apoptosis in vivo. This cell killing effects may be attributed to the enhanced antibodydependent cell-mediated cytotoxicity (ADCC) by natural killer (NK) cells. Abundant evidence demonstrates that one of the major mechanisms of action of trastuzumab is through its IgG1 humanized Fc portion to activate ADCC via host's innate immune system [32]. In addition, cellular adaptive immune response also plays an important role in the clinical efficacy of trastuzumab [39]. Novel strategies that enhance ADCC effectors, such as NK cells, are sought to improve trastuzumab efficacy. A recent study reported exciting data indicating that stimulation of NK cells with a CD137-specific Ab significantly enhanced trastuzumab-mediated cell killing in both sensitive and resistant cell lines in vitro and in vivo [40]. In our case, although MM-121 itself cannot trigger ADCC, because of its IgG2 isotype [41], it is possible that inactivation of erbB3 with MM-121 may increase trastuzumab's binding efficiency to the tumor xenografts-established from BT474-HR20 cells, and subsequently enhance trastuzumab-mediated ADCC.

Activation of erbB3 generally signals through PI-3K/ Akt, MEK/MAPK, Jak/Stat pathways, and Src kinase to modulate many downstream regulators that play a pivotal role in maintaining malignant phenotype, including cell survival, resistance, angiogenesis, and invasion $[16,42]$. Our data showed that treatment of certain erbB2+ breast cancer cell lines with MM-121 resulted in a dramatic inhibition on PI-3K/Akt signaling, the major determinant of trastuzumab resistance in breast cancer [27]. However, it is not known whether MM-121 may potentially abrogate resistance to lapatinib, another erbB2-targeted therapy to treat metastatic breast cancer that has progressed after trastuzumab-based therapy [43]. Lapatinib and trastuzumab may not share common mechanism of resistance, as lapatinib has activity in trastuzumab-resistant breast cancer [44-47]. Some studies show that lapatinib exerts antitumor activity in a PTEN independent manner [48], whereas others report that loss of PTEN and the resulting activation of PI-3K/Akt signaling lead to lapatinib resistance [49]. Thus, it will be very interesting, and may have clinical implications, to study if the combinations of MM121 and lapatinib may synergistically or additively induce growth inhibition and/or apoptosis in BT474-HR20 and SKBR3-pool2 cells. In addition, activation of the erbB2/ erbB3/PI-3K/Akt signaling also results in resistance to hormonal therapy [50] and chemotherapy [51] in breast 


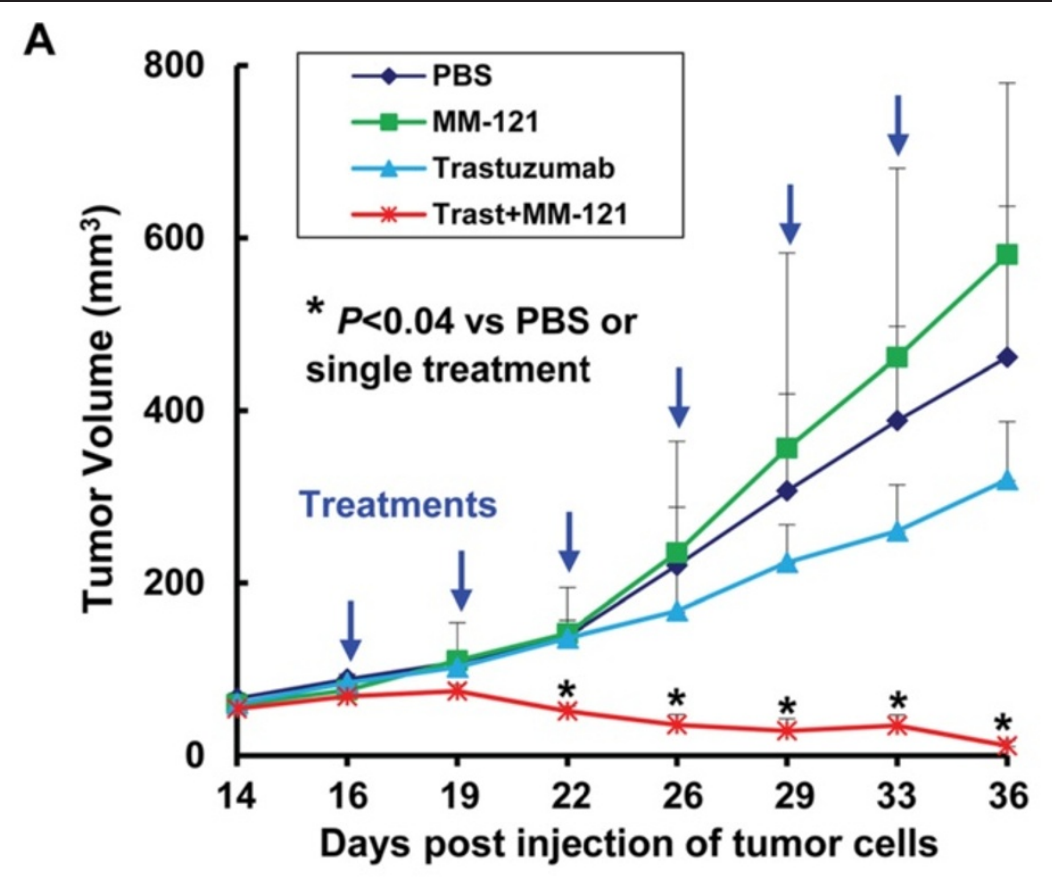

B

PBS

MM-121

Trastuzumab

Trast+MM-121
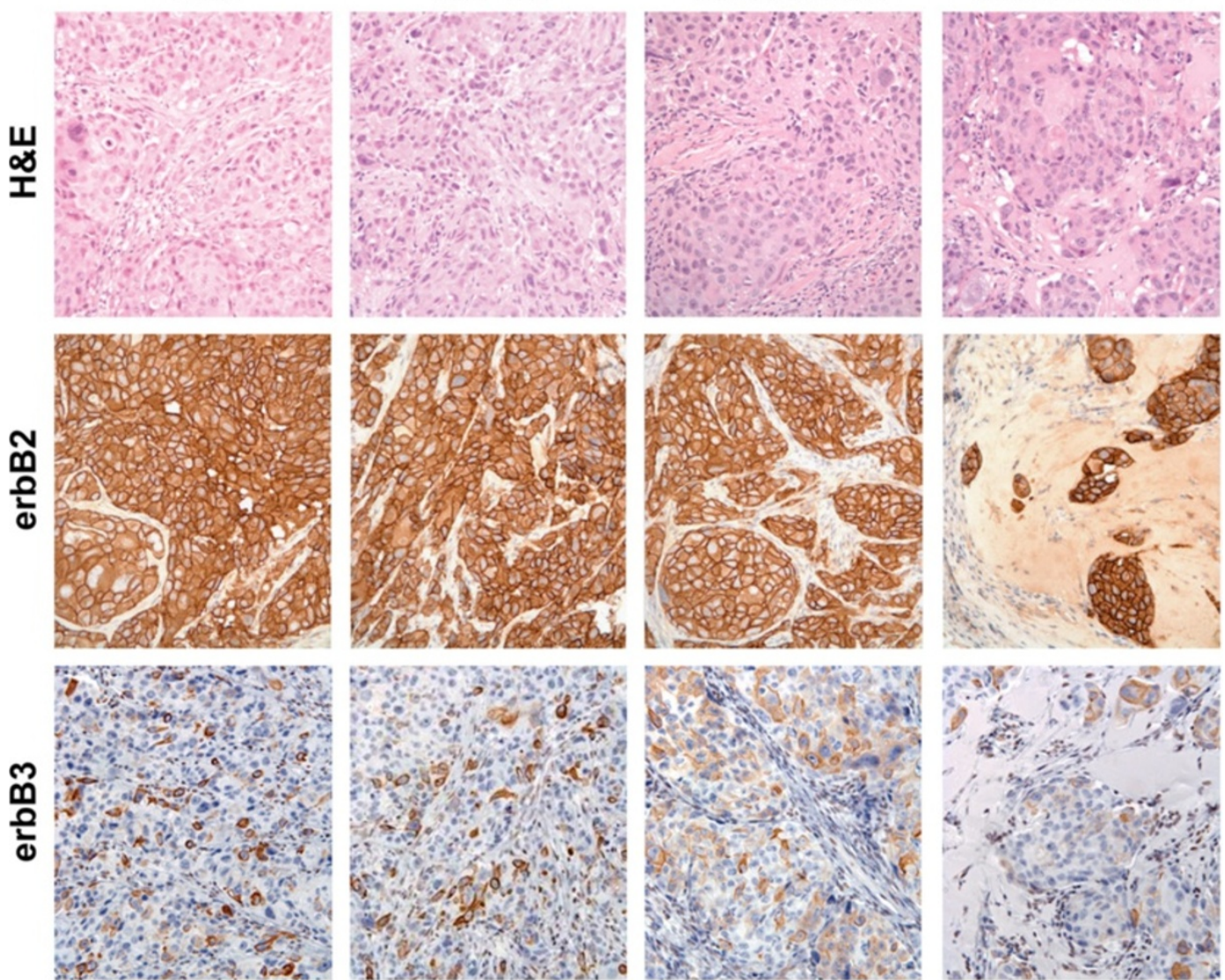

Figure $\mathbf{5}$ (See legend on next page.) 
(See figure on previous page.)

Figure 5 MM-121 in combination with trastuzumab significantly inhibits in vivo growth of tumor xenografts established from BT474-HR20 trastuzumab-resistant breast cancer cells. BT474-HR20 cells were s.c. injected into nude mice to establish tumor xenografts. The tumor-bearing mice $(n=5)$ received i.p. injections of PBS, trastuzumab, MM-121, or trastuzumab plus MM-121 as described in the Materials and Methods. After 6 treatments, the mice were euthanized at day 36 post injection of tumor cells, and all tumors were excised for histology and IHC analysis. A, The graphs show the tumor growth curves. Bars, SD. The combinations of MM-121 and trastuzumab significantly inhibited tumor growth as compared to control or single Ab treatment. B, Data show the representative tumors with hematoxylin and eosin (H\&E) staining and IHC analysis of erbB2 and erbB3. The residual tumor cells obtained from combinatorial treatments retained similar expression levels of erbB2/ erbB3 receptors on the cell membrane.

cancer treatment. We have reported that elevated expression of erbB3 confers paclitaxel resistance in erbB2+ breast cancer cells via a PI-3K/Akt-dependent mechanism [25]. Because MM-121 mainly inhibits activation of erbB3 and Akt (Figures 1 \& 2), it is conceivable to hypothesize that MM-121 may abrogate erbB3 signaling-mediated resistance to paclitaxel as well. Indeed, we have discovered that MM-121 is able to overcome paclitaxel resistance and enhance paclitaxel-induced apoptosis in the otherwise resistant breast cancer cell lines. The manuscript containing those data is submitted separately.

\section{Conclusions}

MM-121 significantly enhances trastuzumab-induced growth inhibition in erbB2+ breast cancer cell lines. MM-121 is active to overcome trastuzumab resistance in the studied in vitro and in vivo models. When combined with trastuzumab, MM-121 mainly inhibits proliferation, without induction of apoptosis, via cell cycle G1 arrest in vitro. However, their combinatorial in vivo antitumor activity against the trastuzumab-resistant breast cancer cells is attributed to induction of both growth inhibition and apoptosis. Our data support further studies to explore the therapeutic potential of MM-121 in combination with trastuzumab in breast cancer patients whose tumors overexpress erbB2 and become resistant to trastuzumab.

\section{Methods}

\section{Reagents and antibodies}

MM-121 was kindly provided by Merrimack Pharmaceuticals, Inc. (Cambridge, MA). Trastuzumab (Herceptin ${ }^{\circledR}$, Genentech, South San Francisco, CA) was obtained from University of Colorado Hospital pharmacy. Antibodies used for western blots were as follows: erbB2 (EMD Chemicals, Inc., Gibbstown, NJ); erbB3 and P-erbB2 (Tyr1248) (LabVision Corp., Fremont, CA); P-erbB3 (Tyr1289), P-MAPK (Thr202/Tyr204), MAPK, P-Akt (Ser473), and Akt (Cell Signaling Technology, Inc., Beverly, MA); Cyclin D1 (M-20), E2F1 (KH95), and p27 ${ }^{\text {kip1 }}$ (F-8) (Santa Cruz Biotechnology, Inc., Santa Cruz, CA); and $\beta$-actin (Sigma Co., St. Louis, MO). All other reagents were purchased from Sigma unless otherwise specified.

\section{Cells and cell culture}

Human breast cancer cell lines SKBR3 and BT474 were obtained from the American Type Culture Collection (ATCC, Manassas, VA). The trastuzumab-resistant sublines SKBR3-pool2 and BT474-HR20, derived from SKBR3 and BT474, respectively, were described previously [26]. All cell lines were maintained in DMEM/ F-12 (1:1) medium (Sigma) containing 10\% fetal bovine serum (Sigma), and cultured in a $37^{\circ} \mathrm{C}$ humidified atmosphere containing 95\% air and 5\% CO2 and split twice a week.

\section{Cell proliferation assay}

The CellTiter96 AQ nonradioactive cell proliferation kit (Thermo Fisher Scientific Inc., Waltham, MA) was used to determine cell viability as previously described $[25,26]$. Briefly, cells were plated onto 96-well plates for $24 \mathrm{~h}$, and then grown in either DMEM/F12 medium with 0.5\% FBS as control, or the same medium containing different concentrations of trastuzumab in the presence or absence of MM-121, and then incubated for another $72 \mathrm{~h}$. After reading all wells at $490 \mathrm{~nm}$ with a microplate reader, the percentages of surviving cells from each group relative to controls, defined as $100 \%$ survival, were determined by reduction of MTS.

\section{Cell cycle analysis}

Flow cytometric assays were performed as described previously [52] to define the cell cycle distribution. In brief, cells grown in culture dishes were harvested by trypsinization and fixed with 70\% ethanol. Cells were stained for total DNA content with a solution containing $50 \mu \mathrm{g} / \mathrm{ml}$ propidium iodide and $100 \mu \mathrm{g} / \mathrm{ml}$ RNase I in PBS for $30 \mathrm{~min}$ at $37^{\circ} \mathrm{C}$. Cell cycle distribution was analyzed at the Flow Cytometry Core Facility of University of Colorado Cancer Center with a FACScan flow cytometer (BD Biosciences, San Jose, CA).

\section{Western blot analysis}

Protein expression levels were determined by western blot analysis as described previously [26,30,52]. Equal amounts of total cell lysates were boiled in Laemmli SDS-sample buffer, resolved by SDS-PAGE, transferred to nitrocellulose membrane (Bio-Rad Laboratories, 


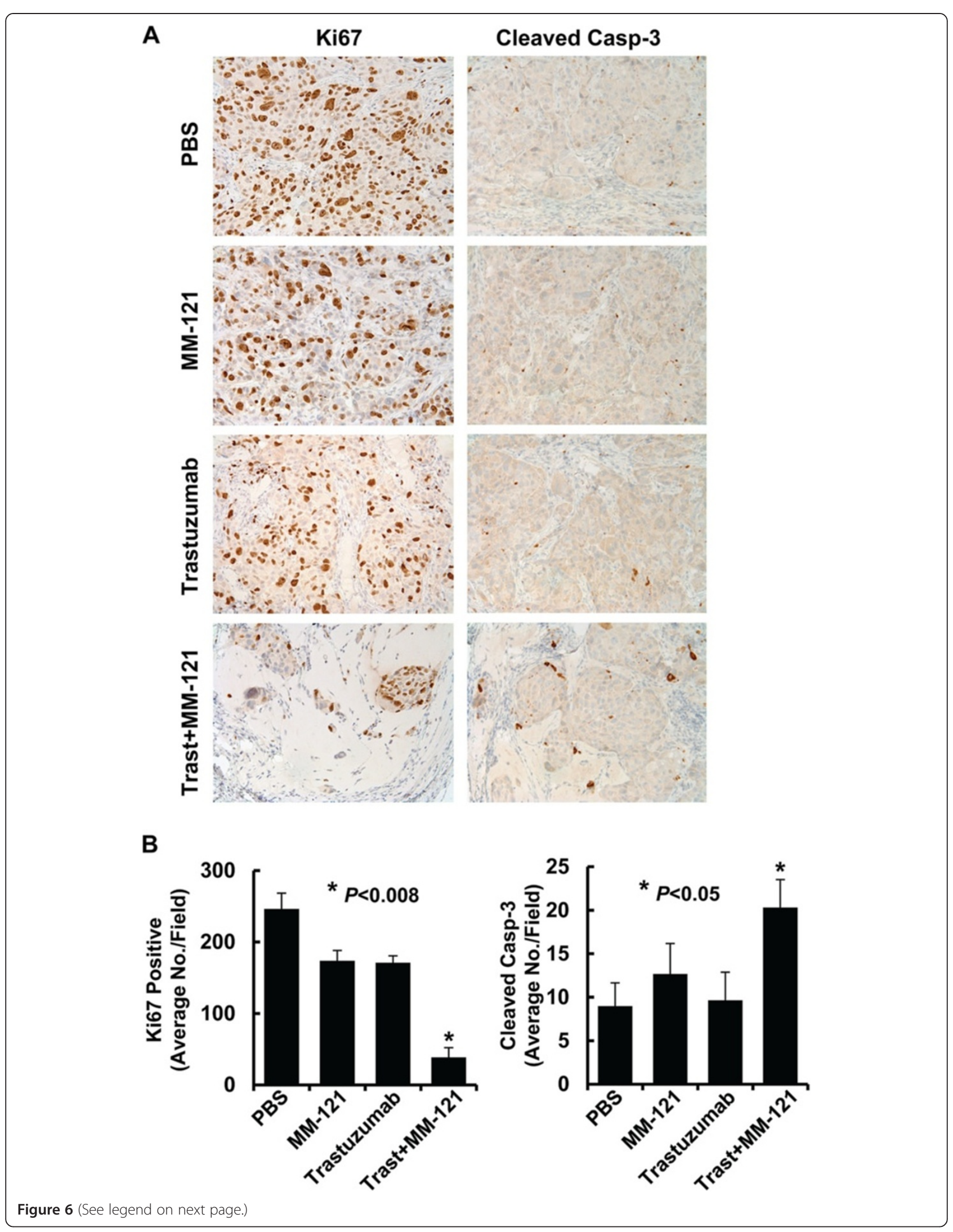


(See figure on previous page.)

Figure 6 The combination of MM-121 and trastuzumab significantly inhibits proliferation and induces apoptosis of trastuzumab-resistant BT474-HR20 breast cancer cells in vivo. The tumors obtained from the animal studies described above were evaluated by $\mathrm{HC}$ analysis of Ki67 and cleaved caspase-3. A, Data show the representative images of the immunostaining of Ki67 and cleaved caspase-3 (Cleaved Casp-3). B, The IHC slides were observed by two independent personnel. The tumor cells with positive staining of Ki67 or cleaved caspase-3 were counted from three randomly selected areas in each slide. The three areas were first identified by scanning the entire slide at $\times 10$ magnification, and then the positive staining cells were counted at $\times 20$ magnification using an Olympus BX40 Microscope. The bar graphs show the average of positive staining cells in each field. Bars, SD. The combinatorial treated mice had significantly fewer cells stained positive for Ki67 and more cells stained positive for cleaved caspase-3 than control mice or single Ab treated mice, $P<0.008$ and $P<0.05$, respectively.

Hercules, CA), and probed with the primary antibodies described in the figure legends. After the blots were incubated with horseradish peroxidase-labeled secondary antibody (Jackson ImmunoResearch Laboratories, West Grove, PA), the signals were detected using the enhanced chemiluminescence reagents (GE Healthcare Bio-Sciences Corp., Piscataway, NJ).

\section{Immunohistochemistry}

Five micron thick paraffin sections were deparaffinized, antigens unmasked and immunohistochemically stained for Ki67 (Thermo Fisher Scientific; rabbit monoclonal SP6; cat\# RM-9106-SO; dilution 1:500 in TBST + 1\% BSA w/v), cleaved Caspase-3 (Cell Signaling Technology; rabbit polyclonal; cat\#: 9661, 1:1000 in TBST + 1\% BSA w/v), erbB2 (EMD Chemicals; mouse monoclonal 96G; cat\#OP14T; dilution 1:500 in TBST + 1\% BSA w/v), and erbB3 (Spring Bioscience, Pleasanton, CA; rabbit monoclonal SP71; cat\# M3710; dilution 1:200 in TBST + 1\% BSA w/v). The specificity of all antibodies has been confirmed by both positive and negative controls. For erbB2 and erbB3, SKBR3 cells were used as a positive control. For Ki67 and cleaved caspase-3, the human tonsil tissues were used a positive control. All the negative controls were performed with the same cells/tissues without addition of the primary antibodies.

Ki67 and cleaved caspase-3 antigens were revealed in pH 9.5 BORG solution (Biocare Medical, Concord, CA) for $5 \mathrm{~min}$ at $125^{\circ} \mathrm{C}$ (22 psi; Decloaking chamber, Biocare). ErbB2 required modest retrieval in $10 \mathrm{mmol} / \mathrm{L}$ sodium citrate for $5 \mathrm{~min}$ at $125^{\circ} \mathrm{C}$ in the Decloaking chamber. ErbB3 required retrieval in Cell Conditioner 1 (standard retrieval time, Ventana). Immunodetection of Ki67, cleaved Caspase- 3 and erbB2 was performed on the NexES stainer (Ventana Medical Systems, Tucson, AZ) at an operating temperature of $37^{\circ} \mathrm{C}$. Ki67 and cleaved caspase- 3 antibodies were incubated for $32 \mathrm{~min}$ and detected with a modified I-VIEW DAB (Ventana) detection kit. The I-VIEW secondary antibody and enzyme were replaced with a species specific secondary antibody (biotinylated goat anti-rabbit; 1:75; cat\# 111-065-144; Jackson ImmunoResearch; $8 \mathrm{~min}$ ) and streptavidinhorseradish (SA-HRP; 1:50; cat\# SA-5004; DAKO Cytomation, Carpinteria, CA; 8 min). ErbB2 was incubated for $32 \mathrm{~min}$ and detected with the standard I-VIEW detection. ErbB3 was incubated for $32 \mathrm{~min}$ and detected with a modified I-VIEW DAB kit in which the secondary antibody was replaced with Rabbit ImmPress (Vector Labs; Burlingame, CA; cat\# MP-7401; 8 minutes at $37^{\circ} \mathrm{C}$ ) and enzyme was replaced with Rabbit ImmPress (Diluted 1:1 in PBS pH 7.6; 8 minutes at $37^{\circ} \mathrm{C}$ ). Sections were sequentially blocked for $10 \mathrm{~min}$ in $3 \%$ hydrogen peroxide (v/v) and $30 \mathrm{~min}$ in Rodent Block M (Biocare, cat\# RBM961), followed by primary antibody incubation for $30 \mathrm{~min}$ and $30 \mathrm{~min}$ in polymer. Antibody complexes were visualized with IP Flex DAB (Biocare; cat\# IPK5010 G80; 4.5\%). All sections were counterstained in Mayer's hematoxylin for $2 \mathrm{~min}$, nuclei blued in $1 \%$ ammonium hydroxide (v/v), dehydrated in graded alcohols, cleared in xylene and coverglass mounted using synthetic resin.

\section{Tumor xenograft model}

Athymic nu/nu mice (Harlan Laboratories, Inc., Indianapolis, IN) were maintained in accordance with the Institutional Animal Care and Use Committee (IACUC) procedures and guidelines. Eight $\times 10^{6}$ BT474-HR20 cells were suspended in $100 \mu \mathrm{L}$ of PBS, mixed with $50 \%$ Matrigel (BD Biosciences) and injected subcutaneously (S.C.) into the flanks of 5-week-old female mice. Tumor formation was assessed by palpation and measured with fine calipers three times a week. Tumor volume was calculated by the formula: volume $=\left(\right.$ length $\times$ width $\left.^{2}\right) / 2$, where length was the longest axis and width the measurement at a right angle to the length, and followed by statistical analysis as we described previously [52]. When tumors reach $\sim 65 \mathrm{~mm}^{3}$, mice were randomly assigned to four groups $(n=5)$ : 1$)$ control group-mice received intraperitoneally (i.p) injection of $100 \mu \mathrm{l}$ PBS only; 2) mice received i.p. injection of trastuzumab $(10 \mathrm{mg} / \mathrm{kg})$ in $100 \mu \mathrm{l}$ PBS twice a week; 3) mice received i.p. injection of MM-121 (10 mg/kg) in $100 \mu \mathrm{l}$ PBS twice a week; 4) mice received i.p. injection of trastuzumab $(10 \mathrm{mg} / \mathrm{kg})$ and MM$121(10 \mathrm{mg} / \mathrm{kg})$ in $100 \mu \mathrm{l}$ PBS twice a week. The animals' health status was monitored daily for weight loss or for signs of altered motor while in their cages. At the end of study, mice were euthanized according to approved IACUC protocol. Tumors from all animals were excised and embedded in paraffin for immunohistochemical analyses. 


\section{Statistical analysis}

Statistical analyses of the experimental data were performed using either a two-sided t test or ANOVA for each time point followed by post-hoc testing between groups. Significance was set at a $\mathrm{P}$ value of $<0.05$. All statistical analyses were conducted with the software StatView v5.1 from SAS Institute Inc., Cary, NC.

\section{Additional files}

Additional file 1: Figure S1. Combinations of trastuzumab and MM-12 significantly induced cell cycle G1 arrest in both trastuzumab-sensitive and -resistant breast cancer cells. SKBR3, BT474, SKBR3-pool2, or BT474-HR20 cells were untreated or treated with either trastuzumab $(20 \mu \mathrm{g} / \mathrm{ml})$ or MM-121 $(10 \mu \mathrm{g} / \mathrm{ml})$ alone, or their combinations for $24 \mathrm{hrs}$. All the cells were collected for analysis of cell cycle distributions by flow cytometry as described in the Methods. The bar graphs show the percentages of the cells at G1 phase for each sample relative to controls, defined as 100\%. A, The combinations of trastuzumab and MM-121 as compared to trastuzumab significantly induced G1 arrest in SKBR3 cells. There was no significant difference between these two treatments in BT474 cells, which was very sensitive to the treatment of trastuzumab alone. B, The combinations of trastuzumab and MM-121 as compared to trastuzumab significantly induced G1 arrest in both SKBR3-pool2 and BT474-HR2O cells. Bars, SD. Statistical analyses were performed using data from three independent experiments.

Additional file 2: Figure S2. Trastuzumab-resistant breast cancer cells show significant growth advantage as compared to their sensitive counterpart and retain their resistant phenotype in vivo. A, BT474 or BT474-HR20 cells were injected s.c into the flanks of 5-week-old female nude mice. Mice were checked for tumor formation three times per week. Tumor volume was calculated by the formula: volume $=\left(\right.$ length $\times$ width $\left.^{2}\right) / 2$ and expressed as cubic millimeters. B \& C, When tumor volumes reached $\sim 65 \mathrm{~mm}^{3}$, the animals were treated with either control (PBS) or trastuzumab $(20 \mathrm{mg} / \mathrm{kg}$ ) four times. Tumors-derived from BT474-HR20 cells were still growing even in the presence of trastuzumab (B), whereas the tumors-derived from BT474 cells were no longer detectable after three doses of trastuzumab (C). Tumor volume was expressed as cubic millimeters (mean $\pm S E ; n=5 /$ group).

Additional file 3: Figure S3. Combinations of trastuzumab and MM-121 significantly increase the percentage of positive-staining cells with cleaved caspase-3 in vivo. The tumor $\mathrm{IHC}$ slides were observed by two independent personnel. The tumor cells with positive staining of cleaved caspase-3 were counted from three randomly selected areas (a total of 360 tumor cells were counted for each area) in each slide. The three areas were first identified by scanning the entire slide at $\times 10$ magnification, and then the positive staining cells were counted at $\times 20$ magnification using an Olympus $B \times 40$ Microscope. The bar graphs show the percentage of cells with positive staining for cleaved caspase-3 from each group. The combinatorial treated mice had significantly higher proportion of cells stained positive for cleaved caspase-3 than the control mice or single Ab treated mice, $P<0.002$

\section{Abbreviations}

MBC: Metastatic breast cancer; RTK: Receptor tyrosine kinase; ER: Estrogen receptor; PR: Progestrone receptor; EGFR: Epidermal growth factor receptor; HRG: Heregulin; IGF-I: Insulin-like growth factor-I; IGF-1R: IGF-I receptor; PTEN: Phosphatase and tensin homolog; PI-3K: Phosphoinositide 3-kinase; MAPK: Mitogen-activated protein kinase; ADCC: Antibody-dependent cell-mediated cytotoxicity; NK: Natural killer; IHC: Immunohistochemistry; ELISA: Enzyme-linked immunosorbent assay; MTS: 3-(4,5-dimethylthiazol-2-yl)-5(3-carboxymethoxyphenyl)-2-(4-sulfophenyl)-2H-tetrazolium,inner salt.

\section{Competing interests}

The authors declare that they have no competing interests.

\section{Authors' contributions}

The authors' contributions to this research work are reflected in the order shown, with the exception of JW and BL who supervised the research and finalized the report. $\mathrm{JH}$ and SW carried out the majority of the in vitro studies and all of the in vivo experiments. $\mathrm{HL}$ generated the data of cell cycle analysis. $\mathrm{JH}$ and $\mathrm{BC}$ performed $\mathrm{IHC}$ studies and quantified the immunostaining. JW and BL drafted the manuscript. XY generated the BT474-HR2O resistant cell line and maintained its resistant phenotype in cell culture. $X Y, J W$, and BL conceived of the study, and participated in its design and coordination. All authors read and approved the final manuscript.

\section{Acknowledgements}

The authors are grateful to Dr. William Kubasek (Merrimack Pharmaceuticals Inc.) for providing MM-121, to Dr. Francisco Esteva (UT MD Anderson Cance Center) for providing SKBR3-pool2 cells, and to Ms. Lisa Litzenberger for her excellent assistance in arts preparation. This work was supported in part by a grant from Susan G. Komen for the Cure (BCTR0707449), AWD-102888 grant from the Cancer League of Colorado, and a pilot award of the Colorado CTSA grant UL1TR000154 from NCATS/NIH (to BL). This work was also supported in part by National Natural Science Foundation of China (No. 81272922) (to SW).

\section{Author details}

${ }^{1}$ Department of Pathology, School of Medicine, University of Colorado Anschutz Medical Campus, MS-8104, 12801 E. 17th Ave., Aurora, CO 80045, USA. ${ }^{2}$ State Key Laboratory of Experimental Hematology, Institute of Hematology and Blood Disease Hospital, 288 Nanjing Road, Tianjin 300020, China. ${ }^{3}$ Julius L. Chambers Biomedical/Biotechnology Research Institute, North Carolina Central University, Kannapolis, NC, USA. ${ }^{4}$ Fujian Key Laboratory of Transplant Biology, Fuzhou General Hospital, Xiamen University, Fuzhou, Fujian, China.

Received: 26 July 2013 Accepted: 7 November 2013

Published: 11 November 2013

\section{References}

1. Slamon DJ, Clark GM, Wong SG, Levin WJ, Ullrich A, McGuire WL: Human breast cancer: correlation of relapse and survival with amplification of the HER-2/neu oncogene. Science 1987, 235:177-182.

2. Wright C, Angus B, Nicholson S, Sainsbury JR, Cairns J, Gullick WJ, Kelly P, Harris AL, Horne $\mathrm{CH}$ : Expression of c-erbB-2 oncoprotein: a prognostic indicator in human breast cancer. Cancer Res 1989, 49:2087-2090.

3. Thor AD, Schwartz LH, Koerner FC, Edgerton SM, Skates SJ, Yin S, McKenzie SJ, Panicali DL, Marks PJ, Fingert HJ, Wood WC: Analysis of c-erbB-2 expression in breast carcinomas with clinical follow-up. Cancer Res 1989, 49:7147-7152.

4. Hudis CA: Trastuzumab-mechanism of action and use in clinical practice. N Engl J Med 2007, 357:39-51.

5. Slamon DJ, Leyland-Jones B, Shak S, Fuchs H, Paton V, Bajamonde A Fleming T, Eiermann W, Wolter J, Pegram M, et al: Use of chemotherapy plus a monoclonal antibody against HER2 for metastatic breast cancer that overexpresses HER2. N Engl J Med 2001, 344:783-792.

6. Vogel CL, Cobleigh MA, Tripathy D, Gutheil JC, Harris LN, Fehrenbacher L, Slamon DJ, Murphy M, Novotny WF, Burchmore M, et al: Efficacy and safety of trastuzumab as a single agent in first-line treatment of HER2-overexpressing metastatic breast cancer. J Clin Oncol 2002, 20:719-726.

7. Nahta R, Esteva FJ: Trastuzumab: triumphs and tribulations. Oncogene 2007, 26:3637-3643.

8. Nahta R, Yu D, Hung MC, Hortobagyi GN, Esteva FJ: Mechanisms of Disease: understanding resistance to HER2-targeted therapy in human breast cancer. Nat Clin Pract Oncol 2006, 3:269-280.

9. Valabrega G, Montemurro F, Aglietta M: Trastuzumab: mechanism of action, resistance and future perspectives in HER2-overexpressing breast cancer. Ann Oncol 2007, 18:977-984.

10. Yu D, Hung MC: Overexpression of ErbB2 in cancer and ErbB2-targeting strategies. Oncogene 2000, 19:6115-6121.

11. Stern DF: ERBB3/HER3 and ERBB2/HER2 duet in mammary development and breast cancer. J Mammary Gland Biol Neoplasia 2008, 13:215-223.

12. Bieche I, Onody P, Tozlu S, Driouch K, Vidaud M, Lidereau R: Prognostic value of ERBB family mRNA expression in breast carcinomas. Int J Cancer 2003, 106:758-765. 
13. de Fazio A, Chiew YE, Sini RL, Janes PW, Sutherland RL: Expression of c-erbB receptors, heregulin and oestrogen receptor in human breast cell lines. Int J Cancer 2000, 87:487-498

14. Lee-Hoeflich ST, Crocker L, Yao E, Pham T, Munroe X, Hoeflich KP, Sliwkowski MX, Stern HM: A central role for HER3 in HER2-amplified breast cancer: implications for targeted therapy. Cancer Res 2008, 68:5878-5887.

15. Holbro T, Beerli RR, Maurer F, Koziczak M, Barbas CF 3rd, Hynes NE: The ErbB2/ErbB3 heterodimer functions as an oncogenic unit: ErbB2 requires ErbB3 to drive breast tumor cell proliferation. Proc Natl Acad Sci USA 2003, 100:8933-8938.

16. Citri A, Skaria KB, Yarden Y: The deaf and the dumb: the biology of ErbB-2 and ErbB-3. Exp Cell Res 2003, 284:54-65.

17. Shi F, Telesco SE, Liu Y, Radhakrishnan R, Lemmon MA: ErbB3/HER3 intracellular domain is competent to bind ATP and catalyze autophosphorylation. Proc Natl Acad Sci USA 2010, 107:7692-7697.

18. Schoeberl B, Faber AC, Li D, Liang MC, Crosby K, Onsum M, Burenkova O, Pace $E$, Walton Z, Nie L, et al: An ErbB3 antibody, MM-121, is active in cancers with ligand-dependent activation. Cancer Res 2010, 70:2485-2494.

19. Schoeberl B, Pace EA, Fitzgerald JB, Harms BD, Xu L, Nie L, Linggi B, Kalra A, Paragas $V$, Bukhalid $R$, et al: Therapeutically targeting ErbB3: a key node in ligand-induced activation of the ErbB receptor-PI3K axis. Sci Signal 2009, 2:ra31.

20. Huang S, Li C, Armstrong EA, Peet CR, Saker J, Amler LC, Sliwkowski MX Harari PM: Dual targeting of EGFR and HER3 with MEHD7945A overcomes acquired resistance to EGFR inhibitors and radiation. Cancer Res 2013, 73:824-833.

21. McDonagh CF, Huhalov A, Harms BD, Adams S, Paragas V, Oyama S, Zhang B, Luus L, Overland R, Nguyen S, et al: Antitumor activity of a novel bispecific antibody that targets the ErbB2/ErbB3 oncogenic unit and inhibits heregulin-induced activation of ErbB3. Mol Cancer Ther 2012, 11:582-593.

22. Foreman PK, Gore M, Kobel PA, Xu L, Yee H, Hannum C, Ho H, Wang SM, Tran HV, Horowitz M, et al: ErbB3 inhibitory surrobodies inhibit tumor cell proliferation in vitro and in vivo. Mol Cancer Ther 2012, 11:1411-1420.

23. Amin DN, Campbell MR, Moasser MM: The role of HER3, the unpretentious member of the HER family, in cancer biology and cancer therapeutics. Semin Cell Dev Biol 2010, 21:944-950.

24. Liu B, Ordonez-Ercan D, Fan Z, Edgerton SM, Yang X, Thor AD: Downregulation of erbB3 abrogates erbB2-mediated tamoxifen resistance in breast cancer cells. Int J Cancer 2007, 120:1874-1882.

25. Wang S, Huang X, Lee CK, Liu B: Elevated expression of erbB3 confers paclitaxel resistance in erbB2-overexpressing breast cancer cells via upregulation of Survivin. Oncogene 2010, 29:4225-4236.

26. Huang X, Gao L, Wang S, McManaman JL, Thor AD, Yang X, Esteva FJ, Liu B: Heterotrimerization of the growth factor receptors erbB2, erbB3, and insulin-like growth factor-i receptor in breast cancer cells resistant to herceptin. Cancer Res 2010, 70:1204-1214.

27. Berns K, Horlings HM, Hennessy BT, Madiredjo M, Hijmans EM, Beelen K, Linn SC, Gonzalez-Angulo AM, Stemke-Hale K, Hauptmann M, et al: A functional genetic approach identifies the PI3K pathway as a major determinant of trastuzumab resistance in breast cancer. Cancer Cell 2007, 12:395-402.

28. Nahta R, Yuan LX, Zhang B, Kobayashi R, Esteva FJ: Insulin-like growth factor-I receptor/human epidermal growth factor receptor 2 heterodimerization contributes to trastuzumab resistance of breast cancer cells. Cancer Res 2005, 65:11118-11128.

29. Nahta R, Takahashi T, Ueno NT, Hung MC, Esteva FJ: P27(kip1) down-regulation is associated with trastuzumab resistance in breast cancer cells. Cancer Res 2004, 64:3981-3986.

30. Liu B, Fan Z, Edgerton SM, Yang X, Lind SE, Thor AD: Potent antiproliferative effects of metformin on trastuzumab-resistant breast cancer cells via inhibition of erbB2/IGF-1 receptor interactions. Cell Cycle 2011, 10:2959-2966.

31. Nahta R, Esteva FJ: Herceptin: mechanisms of action and resistance. Cancer Lett 2006, 232:123-138.

32. Spector NL, Blackwell KL: Understanding the mechanisms behind trastuzumab therapy for human epidermal growth factor receptor 2-positive breast cancer. J Clin Oncol 2009, 27:5838-5847.

33. Pegram MD, Konecny GE, O'Callaghan C, Beryt M, Pietras R, Slamon DJ: Rational combinations of trastuzumab with chemotherapeutic drugs used in the treatment of breast cancer. J Natl Cancer Inst 2004, 96:739-749.
34. Boudeau J, Miranda-Saavedra D, Barton GJ, Alessi DR: Emerging roles of pseudokinases. Trends Cell Biol 2006, 16:443-452.

35. Schulze WX, Deng L, Mann M: Phosphotyrosine interactome of the ErbB-receptor kinase family. Mol Syst Biol 2005, 1:2005 0008.

36. Jathal MK, Chen L, Mudryj M, Ghosh PM: Targeting ErbB3: the new RTK(id) on the Prostate Cancer Block. Immunol Endocr Metab Agents Med Chem 2011, 11:131-149.

37. Mills $G B$, Yarden $Y$ : The rebirth of a phoenix: ovarian cancers are addicted to ErbB-3. Cancer Cell 2010, 17:217-218.

38. Sheng Q, Liu X, Fleming E, Yuan K, Piao H, Chen J, Moustafa Z, Thomas RK, Greulich $\mathrm{H}$, Schinzel $\mathrm{A}$, et al: An activated ErbB3/NRG1 autocrine loop supports in vivo proliferation in ovarian cancer cells. Cancer Cell 2010, 17:298-310.

39. Bellati F, Napoletano C, Ruscito I, Liberati M, Panici PB, Nuti M: Cellular adaptive immune system plays a crucial role in trastuzumab clinical efficacy. J Clin Oncol 2010, 28:e369-e370. author reply e371.

40. Kohrt HE, Houot R, Weiskopf K, Goldstein MJ, Scheeren F, Czerwinski D, Colevas AD, Weng WK, Clarke MF, Carlson RW, et al: Stimulation of natural killer cells with a CD137-specific antibody enhances trastuzumab efficacy in xenotransplant models of breast cancer. J Clin Invest 2012, 122:1066-1075.

41. Jefferis R: Antibody therapeutics: isotype and glycoform selection. Expert Opin Biol Ther 2007, 7:1401-1413.

42. Jin Q, Esteva FJ: Cross-talk between the ErbB/HER family and the type I insulin-like growth factor receptor signaling pathway in breast cancer. J Mammary Gland Biol Neoplasia 2008, 13:485-498.

43. Geyer CE, Forster J, Lindquist D, Chan S, Romieu CG, Pienkowski T, Jagiello-Gruszfeld A, Crown J, Chan A, Kaufman B, et al: Lapatinib plus capecitabine for HER2-positive advanced breast cancer. N Engl J Med 2006, 355:2733-2743.

44. Cameron DA, Stein S: Drug Insight: intracellular inhibitors of HER2-clinical development of lapatinib in breast cancer. Nat Clin Pract Oncol 2008, 5:512-520.

45. McArthur H: An overview of HER-targeted therapy with lapatinib in breast cancer. Adv Ther 2009, 26:263-271.

46. Medina PJ, Goodin S: Lapatinib: a dual inhibitor of human epidermal growth factor receptor tyrosine kinases. Clin Ther 2008, 30:1426-1447.

47. Ryan Q, Ibrahim A, Cohen MH, Johnson J, Ko CW, Sridhara R, Justice R, Pazdur R: FDA drug approval summary: lapatinib in combination with capecitabine for previously treated metastatic breast cancer that overexpresses HER-2. Oncologist 2008, 13:1114-1119.

48. Xia W, Husain I, Liu L, Bacus S, Saini S, Spohn J, Pry K, Westlund R, Stein SH, Spector NL: Lapatinib antitumor activity is not dependent upon phosphatase and tensin homologue deleted on chromosome 10 in ErbB2-overexpressing Breast Cancers. Cancer Res 2007, 67:1170-1175.

49. Eichhorn PJ, Gili M, Scaltriti M, Serra V, Guzman M, Nijkamp W, Beijersbergen RL, Valero V, Seoane J, Bernards R, Baselga J: Phosphatidylinositol 3-kinase hyperactivation results in lapatinib resistance that is reversed by the mTOR/ phosphatidylinositol 3-kinase inhibitor NVP-BEZ235. Cancer Res 2008, 68:9221-9230.

50. Kurokawa $\mathrm{H}$, Arteaga $\mathrm{CL}$ : ErbB (HER) receptors can abrogate antiestrogen action in human breast cancer by multiple signaling mechanisms. Clin Cancer Res 2003, 9:511S-515S.

51. Knuefermann C, Lu Y, Liu B, Jin W, Liang K, Wu L, Schmidt M, Mills GB, Mendelsohn J, Fan Z: HER2/PI-3K/Akt activation leads to a multidrug resistance in human breast adenocarcinoma cells. Oncogene 2003 22:3205-3212

52. Liu B, Fan Z, Edgerton SM, Deng XS, Alimova IN, Lind SE, Thor AD: Metformin induces unique biological and molecular responses in triple negative breast cancer cells. Cell Cycle 2009, 8:2031-2040.

\section{doi:10.1186/1476-4598-12-134}

Cite this article as: Huang et al.: The anti-erbB3 antibody MM-121/ SAR256212 in combination with trastuzumab exerts potent antitumor activity against trastuzumab-resistant breast cancer cells. Molecular Cancer 2013 12:134 